\title{
Journal of

\section{Varying surface hydrophobicities of coatings made of recombinant spider silk proteins}

\author{
Stefanie Wohlrab, $\dagger$ Kristina Spieß $\dagger$ and Thomas Scheibel* \\ Received 30th July 2012, Accepted 6th September 2012 \\ DOI: 10.1039/c2jm35075k
}

\begin{abstract}
The engineered spider silk protein eADF4(C16) reveals similarities to amphiphilic block copolymers. Drop cast of protein solutions on different hydrophobic as well as hydrophilic templates out of different starting solvents (hexafluoroisopropanol, formic acid and aqueous buffers) generated silk films varying in structure and surface properties. Here, the underlying secondary structure of the proteins, the mechanical integrity at increased temperatures, homogeneity and surface topography of silk films, as well as the wettability were investigated in detail. Interestingly, the used templates had impact on microphase separation of the silk molecules as seen by the content of $\beta$-sheet structures; as well as on silk film surface hydrophobicities.
\end{abstract}

\section{Introduction}

Many features of a material, such as wettability or biocompatibility, are determined by its surface. To control interactions of a material with the surrounding environment it is often necessary to modify its surface. Coating of the surface is one possibility to create defined physical and chemical properties. One possibility to coat a substrate is to use self-assembled monolayers (SAMs) of amphiphilic organic molecules and another one is the use of multilayer films. ${ }^{1,2}$ Multilayer films of polypeptides are suitable for applications which encompass some of the following desirable features: anti-fouling, biocompatibility, biodegradability, specific bio-molecular sensitivity, environmental benignity, thermal responsiveness, and stickiness or non-stickiness. ${ }^{3-6}$ Coatings made of silk proteins can address some of these issues by virtue of the biochemical nature of the silk proteins. Especially, spider dragline silk which builds the frame and the radii of a spider web is a promising material for biomedical and technical applications. ${ }^{7}$ Two so far identified components of the dragline silk of the European Garden spider, A. diadematus, are Araneus diadematus fibroin 3 (ADF3) and Araneus diadematus fibroin 4 (ADF4), which resemble amphiphiles with blocks of polyalanine and glycine-rich blocks. ${ }^{8}$ The polyalanines adopt $\beta$-sheet structures which are thought to be responsible for the high tensile strength $^{9}$ in fibres, while the glycine-rich blocks form helical structures or random coil elements, being important for the flexibility and elasticity of fibres. ${ }^{10}$

In contrast to nature, where spider dragline silk proteins are exclusively converted into threads, in vitro it is possible to

Fakultät für Angewandte Naturwissenschaften, Lehrstuhl Biomaterialien, Universität Bayreuth, Universitätsstr.30, D-95440 Bayreuth, Germany. E-mail: Thomas.scheibel@bm.uni-bayreuth.de; Fax: +49 92155 7346; Tel: +49921557361

$\dagger$ These authors contributed equally. produce other two- or three-dimensional shapes, such as e.g. hydrogels,$^{11}$ films ${ }^{12}$ or microparticles. ${ }^{13}$ Here, we intended to create biocompatible surfaces with defined wettability, based on the previously established engineered spider silk protein eADF4(C16). The hydrophilic material glass as well as the technically important hydrophobic substrates polystyrene and Teflon (PTFE) were chosen as model templates. Additionally, different starting solvents such as hexafluoroisopropanol (HFIP), formic acid (FA) and aqueous buffers were investigated, since they have an influence on the structure and mechanical properties of spider silk films. ${ }^{14,15}$

\section{Experimental}

Film preparation

The recombinant spider silk protein eADF4(C16), which consists of 16 repeats of the $C$ module (GSSAAAAAAAASGPGGYG PENQGPSGPGGYGPGGP), was produced and purified as described previously. ${ }^{16}$ The purified and lyophilized protein was directly dissolved in hexafluoroisopropanol (HFIP) or formic acid (FA). To generate an aqueous solution, eADF4(C16) was dissolved in $6 \mathrm{M}$ guanidiniumthiocyanate and dialyzed against aqueous buffer. Ammonium bicarbonate was chosen as the buffer system, since it decomposes into the volatile components $\mathrm{NH}_{3}, \mathrm{CO}_{2}$ and $\mathrm{H}_{2} \mathrm{O}$ upon evaporation. The obtained protein solutions were cast on polystyrene, polytetrafluoroethylene (PTFE) and glass. Since the water content has a large influence on spider silk films, the environmental conditions were kept constant at $30 \%$ relative humidity and $20{ }^{\circ} \mathrm{C}$. After evaporation of the solvent the films were treated with methanol to stabilize the films by inducing $\beta$-sheet structures as described previously. ${ }^{17}$ For contact angle measurements, FTIR analysis, and enzymatic digestion, silk films with a thickness of approximately $1 \mu \mathrm{m}$ were 
employed. For dynamic mechanical analysis, films with a thickness of 9-11 $\mu \mathrm{m}$ were used.

\section{Atomic force microscopy}

For surface morphology characterization, films were analysed in tapping mode using a Dimension ${ }^{\mathrm{TM}} 3100$ Nanscope IV (Veeco Instrument Inc., N.Y., USA). $\mathrm{Si}_{3} \mathrm{~N}_{4}$ cantilevers (Olympus, Tokyo, Japan) were used with a force constant of $42 \mathrm{~N} \mathrm{~m}^{-1}$. The average roughness $R_{\mathrm{a}}$ was calculated in an area of $25 \mu \mathrm{m}^{2}$.

\section{Contact angle measurements}

To analyse the wettability, static contact angles of water on spider silk films were analysed using the OCA contact angle system (Dataphysics Instruments GmbH, Germany). The contact angles were determined using the SCA20 software (Dataphysics Instruments $\mathrm{GmbH}$, Germany) and a Laplace Young fit. Since as-cast HFIP and aqueous films partially dissolve in water, only post-treated films were characterized.

\section{Film digestion}

Silk films were covered with chymotrypsin (Roth, Karlsruhe, Germany) in solution ( $9 \mathrm{U} \mathrm{ml}^{-1}$ in $100 \mathrm{mM}$ Tris, $10 \mathrm{mM} \mathrm{CaCl}_{2}$, $\mathrm{pH}$ 7.8). After $24 \mathrm{~h}$ of incubation at $37^{\circ} \mathrm{C}$, the films were washed with distilled water to remove the enzyme, dried, and analysed by scanning electron microscopy (SEM).

\section{Attenuated total reflections-Fourier transform infrared (ATR- FTIR) spectroscopy}

ATR-FTIR spectra were obtained on a Ge crystal in absorbance mode using a Bruker Tensor 27 spectrometer (Bruker, Germany) between $3500 \mathrm{~cm}^{-1}$ and $750 \mathrm{~cm}^{-1}$. Each measurement reflects 60 scans at a resolution of $2 \mathrm{~cm}^{-1}$. To determine the fractions of individual secondary structures, the amide I region $\left(1595 \mathrm{~cm}^{-1}\right.$ to $1705 \mathrm{~cm}^{-1}$ ) was analysed by Fourier self-deconvolution (FSD) using the Opus software (Bruker Optics Corp., Billerica, MA, USA) according to $\mathrm{Hu}$ et al., 2006. ${ }^{18}$

\section{Scanning electron microscopy (SEM)}

Scanning electron microscopy was performed with a 1450EsB Cross Beam (Zeiss, Germany) at an accelerating voltage of $3 \mathrm{kV}$. After digestion with chymotrypsin the dried silk films were sputtered with platinum and analysed directly.

\section{Dynamic mechanical analysis (DMA)}

Dynamic mechanical analysis was performed with a DMA 2980 (TA Instruments, Newcastle, DE, USA). A frequency of $5 \mathrm{~Hz}$, a heat rate of $2{ }^{\circ} \mathrm{C} \mathrm{min}^{-1}$, and an amplitude of $0.08 \%$ (relative to the initial sample length) were used.

\section{Results and discussion}

\section{Characterization of the silk films}

Silk protein films were cast from different solvents on PTFE, glass and polystyrene, and the homogeneity and the surface topography of substrates were analysed by atomic force microscopy (AFM); followed by calculation of the average roughness $R_{\mathrm{a}}$. Depending on the solvent and the template, the average roughness of the silk films varied in a range from 1.2 to $27.5 \mathrm{~nm}$ (within an area of $25 \mu^{2}$ ) (Table 1). HFIP and formic acid films cast on a glass surface revealed a slightly wavy, relatively smooth surface, whereas films cast on polystyrene were plane with small "spikes". The films cast on PTFE showed a more homogeneous appearance, however, with a higher roughness than films on glass or polystyrene. In contrast to HFIP and FA films, which showed a homogeneous smooth surface, those cast from aqueous solutions were relatively rough and had a peak-shaped structure.

In order to test the stability of the films dynamic mechanical analysis (DMA) was employed. The storage moduli $E^{\prime}$ and loss moduli $E^{\prime \prime}$ similarly changed in all films with increasing temperature. DMA curves for as-cast and methanol-treated films cast from formic acid are shown as typical examples in Fig. 1. At temperatures $<100^{\circ} \mathrm{C}$ a strain hardening effect was observed due to water/solvent loss. Up to temperatures of around $175-205^{\circ} \mathrm{C}$ (depending on the solvent/post-treatment) the initial high storage modulus and the loss modulus slightly changed (Table 2, Fig. 1), followed by a sharp decrease of approximately one order of magnitude in $E^{\prime}$ and $E^{\prime \prime}$. The reached maximum reflected a glass transition-like behaviour with a sudden gain in segmental motion of the protein chains accompanied by a remarkable elongation of the films. A direct correlation between the moduli, the glass transition temperature $T_{\mathrm{g}}$ and the secondary structure was observed. An increase in the $\beta$-sheet content from $20 \%$ (in as cast HFIP films) to $\geq 40 \%$ (in methanol treated films) resulted in an increase in moduli and an upward shift in $T_{\mathrm{g}}$ of $\sim 50{ }^{\circ} \mathrm{C}$, indicating an increase in stability in the case of $\beta$-sheet enriched films.

\section{Wetting behaviour of silk films}

The surface hydrophobicity is important for a material's interaction with its environment. Therefore, the water contact angles (CA) were analysed of the film-air interface. HFIP films made on polystyrene revealed a film-air water contact angle of $38.4^{\circ} \pm$ $6.9^{\circ}$, being more hydrophilic than that of aqueous films $\left(48.2^{\circ} \pm\right.$ $\left.5.8^{\circ}\right)$ and FA films $\left(63.0^{\circ} \pm 4.3^{\circ}\right)$. All films rendered the polystyrene surface more hydrophilic when compared to the uncoated template surface, which displayed a water contact angle of $89.4^{\circ} \pm 1.1^{\circ}$ (Fig. 2A). Additionally, air contact angles of films cast on glass, a more hydrophilic substrate, and of films cast on Teflon, a hydrophobic and technically important substrate, were tested. Strikingly, the surface hydrophobicities of

Table 1 Average roughness $R_{\mathrm{a}} / \mathrm{nm}$ of eADF4(C16) films was determined by AFM (measured in an area of $25 \mu \mathrm{m}^{2}$ ). Films were cast from HFIP, FA or aqueous buffer $\left(10 \mathrm{mM} \mathrm{NH} \mathrm{NHCO}_{3}\right)$ on polystyrene (PS), glass or Teflon (PTFE) and analysed after subsequent processing with methanol

\begin{tabular}{lrlrr}
\hline \multicolumn{5}{c}{ Average roughness $R_{\mathrm{a}} / \mathrm{nm}$} \\
\hline & \multicolumn{1}{c}{ HFIP } & \multicolumn{1}{l}{ FA } & \multicolumn{1}{c}{ Aqueous } & \multicolumn{1}{c}{ Uncoated } \\
\hline Glass & $1.27 \pm 0.48$ & $1.21 \pm 0.41$ & $8.27 \pm 0.94$ & $1.02 \pm 0.21$ \\
PS & $1.97 \pm 0.65$ & $4.73 \pm 2.01$ & $12.24 \pm 2.71$ & $6.16 \pm 1.01$ \\
PTFE & $10.00 \pm 2.50$ & n.d. & $27.50 \pm 4.80$ & $23.30 \pm 6.55$ \\
\hline
\end{tabular}




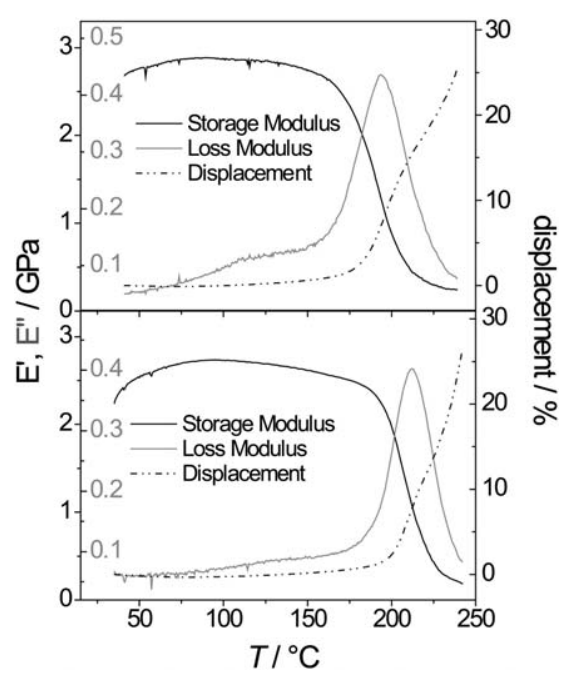

Fig. 1 Storage modulus $E^{\prime}$, loss modulus $E^{\prime \prime}$ and change in the sample length (displacement) of eADF4(C16) films. Exemplary films cast from formic acid, before (upper panel) and after methanol $(\mathrm{MeOH})$ treatment (lower panel) are shown. Dynamic mechanical analysis was performed with a frequency of $5 \mathrm{~Hz}$, a heat rate of $2{ }^{\circ} \mathrm{C} \mathrm{min}^{-1}$, and an amplitude of $0.08 \%$ (relative to the initial sample length).

all coated templates were inversed in comparison to plain template surfaces (non-coated). This trend was visible for films cast from every solvent, with air-surfaces of HFIP films yielding the smallest and FA films the highest (except on glass) water contact angles. Due to the higher roughness of the aqueous films on glass, the films showed increased contact angles. In the case of PTFE $\left(\mathrm{CA}=104.5^{\circ} \pm 3.1^{\circ}\right)$ the air-surface of silk films was hydrophilic $\left(\mathrm{CA}=41-59.2^{\circ}\right)$, while in the case of glass $(\mathrm{CA}=$ $\left.28.2^{\circ} \pm 1.3^{\circ}\right)$ it was hydrophobic $\left(\mathrm{CA}=62.1-113.4^{\circ}\right)$ (Fig. 2A). In addition to the hydrophobicity of the silk film-air interface, the water contact angles of film-template interfaces were analysed. For example HFIP films on PTFE with a hydrophilic air surface $\left(\mathrm{CA}=41.7^{\circ} \pm 6.3^{\circ}\right)$ had a more hydrophobic template surface with water contact angles of $74.4^{\circ} \pm 5.8^{\circ}$ (Fig. $2 \mathrm{~B}$ and C).

\section{Secondary structure analysis of the silk films}

Next, we analysed structural differences of the silk films by ATRFTIR. In the achieved FTIR spectra, the amide I band which represents mainly $\mathrm{C}=\mathrm{O}$ stretching vibrations of the amide backbone and the amide II band which corresponds to $\mathrm{N}-\mathrm{H}$ bending vibrations were both analysed in detail. The $\beta$-sheet content of silk films is highly dependent on the solvent used.

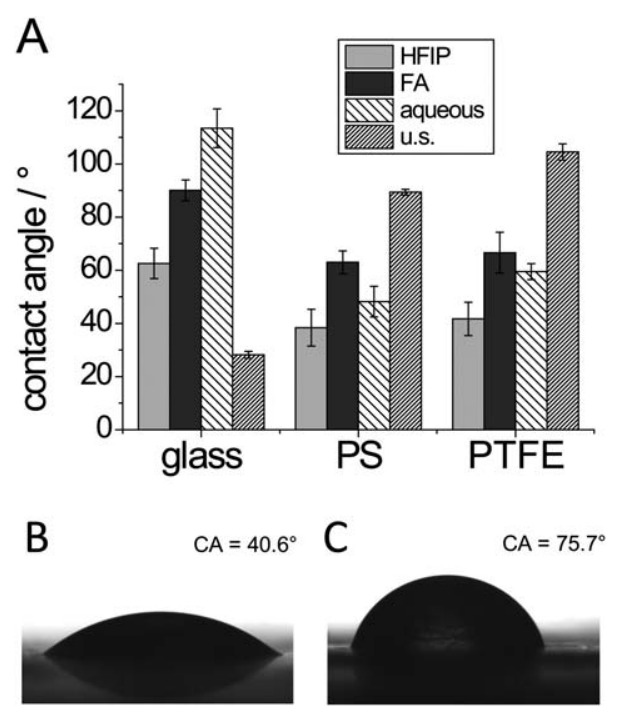

Fig. 2 (A) Surface hydrophobicity of eADF4(C16) films determined by water contact angle measurements. Films were cast on polystyrene, glass or Teflon from HFIP, FA or aqueous buffer $\left(10 \mathrm{mM} \mathrm{NH}_{4} \mathrm{HCO}_{3}\right)$ and analysed after subsequent processing with methanol. As reference, the contact angles of uncoated substrates (u.s.) were determined $\left(28.2 \pm 1.3^{\circ}\right.$ for glass, $89.4 \pm 1.1^{\circ}$ for PS, and $104.5 \pm 3.1^{\circ}$ for Teflon). Exemplary water contact angles are shown of the air surface (B) and the template surface (C) of eADF4(C16) films cast from HFIP on Teflon after methanol treatment.

Fluorinated alcohols, like HFIP, are known to induce an $\alpha$-helical structure, thus silk proteins dissolved in HFIP show a significantly higher helical content. ${ }^{19,15}$ In contrast, formic acid induces $\beta$-sheet structures by interaction with the polar side chains of proteins. ${ }^{21}$

Surprisingly, films cast on hydrophilic substrates showed significant differences to films cast on hydrophobic substrates independent of the solvent used (Fig. 3A). The fraction of individual secondary structures was determined by Fourier SelfDeconvolution (FSD) of the amide I band, as described previously by $\mathrm{Hu}$ et $a{ }^{18}{ }^{18}$ On the hydrophobic substrates PTFE and polystyrene silk films showed significantly higher levels of $\beta$-sheet structures $(41-46 \%)$ than films cast on glass, which had a $\beta$-sheet content of $34-37 \%$ (Fig. 3B). In the case of films cast on glass, the amphiphilic silk proteins form hydrogen bonds with the glass influencing the methanol induced $\beta$-sheet shift of the silk structure. On the hydrophobic substrates polystyrene and PTFE the $\beta$-sheet content of silk films is consequently higher. The difference in $\beta$-sheet content of silk films on polystyrene and PTFE is not significant.

Table 2 Overview of mechanical characteristics (onset drop in storage modulus $E^{\prime}$ and max. loss modulus $\left.E^{\prime \prime} /{ }^{\circ} \mathrm{C}\right)$ of eADF4(C16) films. Dynamic mechanical analysis was performed with a frequency of $5 \mathrm{~Hz}$, a heat rate of $2{ }^{\circ} \mathrm{C} \mathrm{min}^{-1}$, and an amplitude of $0.08 \%$ (relative to the initial sample length)

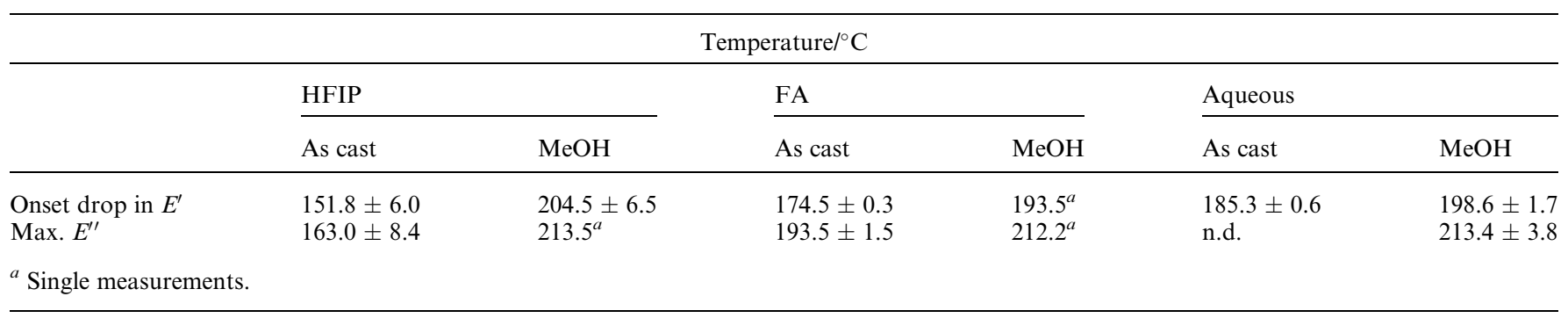



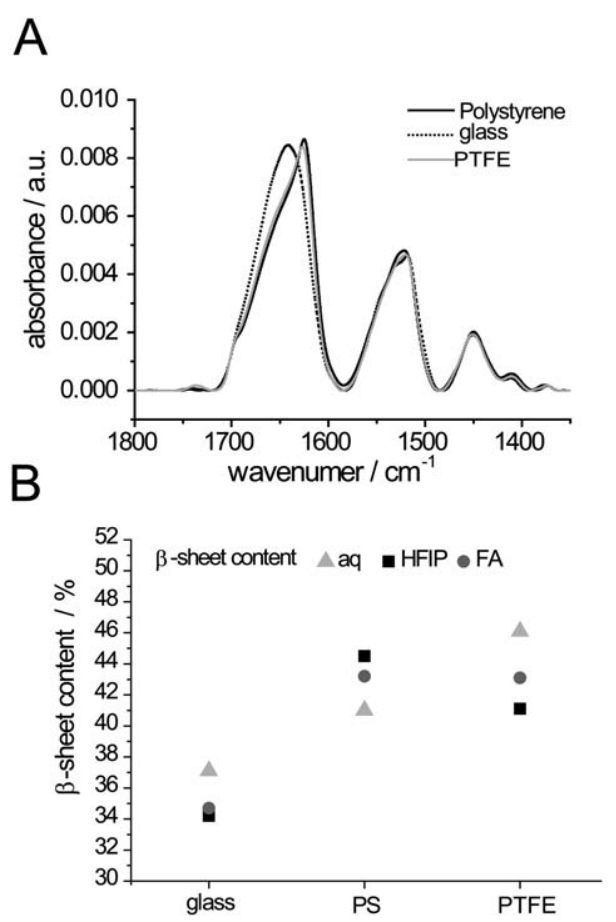

Fig. 3 Influence of template and starting solvent on the secondary structure of eADF4(C16) films. (A) After methanol treatment, the films were analysed by FTIR spectroscopy (exemplary films cast from HFIP are shown). (B) $\beta$-sheet content of eADF4(C16) films. Films were cast on either glass, polystyrene (PS) or Teflon from HFIP (squares), FA (circles) or aqueous buffer (triangle).

\section{Microphase separation of silk proteins}

In polymer chemistry it is well known that block copolymers will arrange differently depending on their composition. Because of the thermodynamic incompatibility of the different blocks, the contact between similar/dissimilar blocks is maximized/minimized; and the self-assembly in micro-domains occurs. ${ }^{21}$ Such microphase separation effects have already been observed for the naturally occurring spider dragline silk, for engineered spider silk proteins, ${ }^{22,23}$ for multi-block copolymers based on spider silk proteins, ${ }^{24,25}$ for cast silk fibroin drops ${ }^{26}$ and for silk fibroin ${ }^{27}$

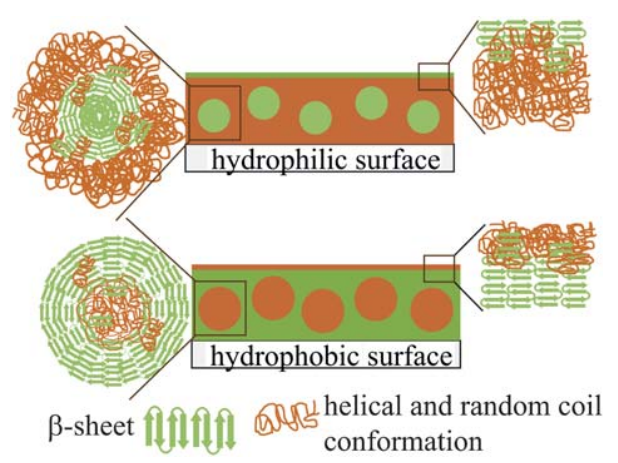

Fig. 4 Influence of the template on the secondary structure of eADF4(C16). A hydrophilic substrate leads to less $\beta$-sheet structures, but $\beta$-sheet exposure at the film-air surface, thus inducing a hydrophobic film surface. In contrast, the air-surface of films on hydrophobic substrates is more hydrophilic. Although a higher overall $\beta$-sheet content is induced on such surface, most $\beta$-sheets are incorporated within the films.

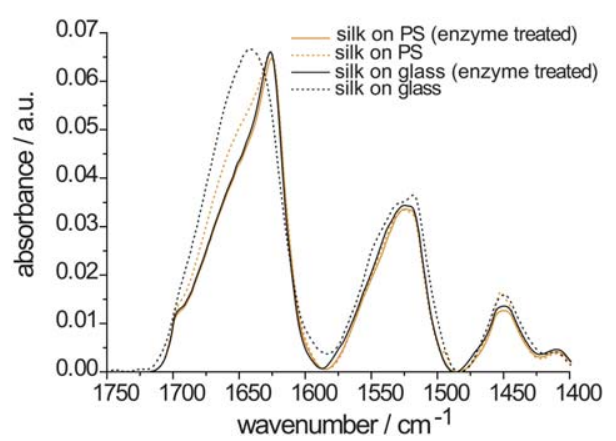

Fig. 5 ATR-FTIR-spectra of silk films cast from HFIP on polystyrene (orange) and from aqueous buffer on glass (black) before (solid lines) and after chymotrypsin treatment (dotted lines).

films, where $\beta$-sheet crystallites are dispersed in an amorphous matrix. $^{28}$

Based on the existing evidences we generated a structural model for silk coating on surfaces based on self-assembled microdomains (Fig. 4). To experimentally confirm the descriptive model of the result of microphase separation, the silk films were digested with chymotrypsin. Previously it had been shown that $\alpha$ chymotrypsin degrades the non-crystalline parts of silk proteins faster than the $\beta$-sheet crystals. ${ }^{29}$ Therefore, the percent content of $\beta$-sheet structures should increase upon $\alpha$-chymotrypsin treatment. This increase in $\beta$-sheet content was indeed seen for silk films treated with chymotrypsin, in dependence of the template the silk film was cast on and as confirmed by FTIR analysis (Fig. 5, Table 3). In the case of films on polystyrene the percent $\beta$-sheet content increased after enzyme treatment from $41.0 \%$ to $46.5 \%$ and in the case of glass from $35.7 \%$ to $45.9 \%$.

Further, the surface morphology of the enzyme-treated films was analysed by scanning electron microscopy (SEM). Films cast on polystyrene had a smooth surface with small pinholes, indicative of a $\beta$-sheet rich surface with small helical inclusions of 50 to $150 \mathrm{~nm}$ in diameter. On glass, the silk surface was much rougher after $\alpha$-chymotrypsin treatment with particulate structures (Fig. 6).

We assume that the phase separation is based on the amphiphilic nature of the silk proteins. ${ }^{30}$ Their poly-alanine stretches can be considered as non-hydrophilic blocks (close interaction, water exclusion), whereas glycine-rich regions can be regarded as hydrophilic blocks. A hydrophilic template, e.g. glass, leads to hydrophobic silk patches (like coalesced micelles) surrounded by more hydrophilic amino acids. Drying of the film and subsequent treatment with methanol induce the folding of the poly-alanines into $\beta$-sheet crystallites, whereas glycine-rich motifs remain
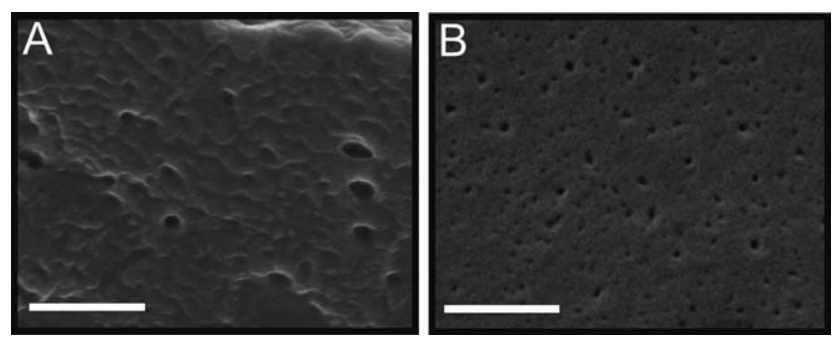

Fig. 6 Scanning electron microscopy (SEM) images of chymotrypsin treated silk films on glass (A) and polystyrene (B). Scale bar $1 \mu \mathrm{m}$. 
Table 3 The percent $\beta$-sheet content of silk films (untreated and enzyme treated) was determined by Fourier Self Deconvolution (FSD) of the amide I band

\begin{tabular}{lll}
\hline & $\beta$-sheet content $\%$ & \\
\hline & Silk film & $\begin{array}{l}\text { Enzyme treated } \\
\text { silk film }\end{array}$ \\
\hline Polystyrene & $41.0 \pm 0.3$ & $46.5 \pm 1.4$ \\
Glass & $35.7 \pm 1.7$ & $45.9 \pm 0.3$ \\
\hline
\end{tabular}

unstructured or in helical (polyproline II) conformations. At the film-air interface the hydrophobic patches are preferentially oriented towards air instead of the mainly hydrophilic bulk, leading to a film surface which appears to be more hydrophobic.

Protein films cast on a hydrophobic substrate consist to a higher degree of $\beta$-sheets, which render the bulk of the film more hydrophobic. The hydrophilic areas consisting of random coil and helical conformations are dispersed therein. At the silk-air interface hydrophilic parts orient towards air instead of the hydrophobic core; and the surface appears to be more hydrophilic being more sensitive to chymotrypsin digestion.

\section{Conclusions}

In summary, we have shown that not only the starting solvent but also the template surface has a significant influence on the properties of drop cast recombinant spider silk films and coatings. The observed possibility to control surface wettability of the films presents a high potential for these coatings in technical and medical fields. Due to the limited bonding ability, silk films can easily be peeled off the hydrophobic surfaces. Since recombinant spider silk proteins can be easily functionalized, introduction of functional groups on a template's surface would allow specific chemical bonding between the template surface and the silk film. ${ }^{12}$ Together with the biocompatibility, the biodegradability and the opportunity of chemical modification, spider silk coatings can for example be used for the optimization or minimization of protein adsorption and cell growth on synthetic biomaterials. $^{12,31,32}$

\section{Acknowledgements}

This work was supported by SFB 840 A8. The authors would like to thank Markus Hund for technical support on AFM measurements and Andrew Smith, Martin Humenik, Lukas Eisoldt and Claudia Blüm for scientific discussions.

\section{Notes and references}

1 M. J. Pellerite, E. J. Wood and V. W. Jones, J. Phys. Chem. B, 2002, 106, 4746-4754.

2 G. Decher, Science, 1997, 277, 1232-1237.

3 D. T. Haynie, L. Zhang, J. S. Rudra, W. H. Zhao, Y. Zhong and N. Palath, Biomacromolecules, 2005, 6, 2895-2913.

4 F. Boulmedais, V. Ball, P. Schwinte, B. Frisch, P. Schaaf and J. C. Voegel, Langmuir, 2003, 19, 440-445.

5 M. Golonka, M. Bulwan, M. Nowakowska, A. M. Testera, J. C. Rodriguez-Cabello and S. Zapotoczny, Soft Matter, 2011, 7, 9402-9409.

6 B. Y. Li and D. T. Haynie, Biomacromolecules, 2004, 5, 1667-1670.

7 K. Spiess, A. Lammel and T. Scheibel, Macromol. Biosci., 2010, 10, 998-1007.

8 S. Winkler and D. L. Kaplan, J. Biotechnol., 2000, 74, 85-93.

9 B. L. Thiel and C. Viney, Science, 1996, 273, 1480-1481.

10 A. E. Brooks, H. B. Steinkraus, S. R. Nelson and R. V. Lewis, Biomacromolecules, 2005, 6, 3095-3099.

11 K. Schacht and T. Scheibel, Biomacromolecules, 2011, 12, 2488-2495.

12 K. Spiess, S. Wohlrab and T. Scheibel, Soft Matter, 2010, 6, 41684174.

13 U. K. Slotta, S. Rammensee, S. Gorb and T. Scheibel, Angew. Chem., Int. Ed., 2008, 47, 4592-4594.

14 U. Slotta, M. Tammer, F. Kremer, P. Koelsch and T. Scheibel, Supramol. Chem., 2006, 18, 465-471.

15 K. Spiess, R. Ene, C. D. Keenan, J. Senker, F. Kremer and T. Scheibel, J. Mater. Chem., 2011, 21, 13594-13604.

16 D. Huemmerich, C. W. Helsen, S. Quedzuweit, J. Oschmann, R. Rudolph and T. Scheibel, Biochemistry, 2004, 43, 13604-13612.

17 D. Huemmerich, U. Slotta and T. Scheibel, Appl. Phys. A: Mater. Sci. Process., 2006, 82, 219-222.

18 X. Hu, D. Kaplan and P. Cebe, Macromolecules, 2006, 39, 6161-6170.

19 K. Gast, A. Siemer, D. Zirwer and G. Damaschun, Eur. Biophys. J. Biophys. Lett., 2001, 30, 273-283.

20 A. Vasconcelos, G. Freddi and A. Cavaco-Paulo, Biomacromolecules, 2008, 9, 1299-1305.

21 S. B. Darling, Prog. Polym. Sci., 2007, 32, 1152-1204.

22 S. Rammensee, U. Slotta, T. Scheibel and A. R. Bausch, Proc. Natl. Acad. Sci. U. S. A., 2008, 105, 6590-6595.

23 K. D. Hermanson, D. Huemmerich, T. Scheibel and A. R. Bausch, Adv. Mater., 2007, 19, 1810.

24 O. Rathore and D. Y. Sogah, Macromolecules, 2001, 34, 2394.

25 J. Cao, M. L. Qi, Y. Zhang, S. Zhou, Q. L. Shao and R. N. Fu, Anal. Chim. Acta, 2006, 561, 88-95.

26 R. Gebhardt, C. Vendrely, M. Burghammer and C. Riekel, Langmuir, 2009, 25, 6307-6311.

27 X. Hu, Q. Lu, D. L. Kaplan and P. Cebe, Macromolecules, 2009, 42, 2079-2087.

28 M. Heim, L. Romer and T. Scheibel, Chem. Soc. Rev., 2010, 39, 156164.

29 T. Arai, G. Freddi, R. Innocenti and M. Tsukada, J. Appl. Polym. Sci., 2004, 91, 2383-2390.

30 J. H. Exler, D. Hummerich and T. Scheibel, Angew. Chem., Int. Ed., 2007, 46, 3559-3562.

31 A. Leal-Egana and T. Scheibel, Biotechnol. Appl. Biochem., 2010, 55, 155-167.

32 S. Wohlrab, S. Muller, A. Schmidt, S. Neubauer, H. Kessler, A. LealEgana and T. Scheibel, Biomaterials, 2012, 33, 6650-6659. 